\title{
O PROBLEMA DO MUNDO DO TRABALHO NO ATUAL CON- TEXTO DA CRISE ESTRUTURAL DO CAPITAL
}

\author{
THE PROBLEM OF THE WORLD OF THE WORK IN THE CURRENT CONTEXT \\ CAPITAL STRUCTURAL CRISIS \\ EL PROBLEMA DEL MUNDO DEL TRABAJO EN EL CONTEXTO EN EL ACTUAL \\ CONTEXTO DE LA CRISIS ESTRUCTURAL DEL CAPITAL
}

\author{
Osterne Nonato Maia Filho \\ Professor Doutor da UECE, da UNIFOR e da UFC. \\ osterne_filho@uol.com.br \\ Maria das Dores Mendes Segundo \\ Professora Doutora da UECE e da UFC. \\ mariadores.segundo@uece.br \\ Josefa Jackline Rabelo \\ Professora Doutora da UFC. \\ jacklinerabelo@uol.com.br
}

RESUMO: No atual momento de crise estrutural do capital, em que as forças produtivas são reconfiguradas na forma de produção destrutiva, a classe trabalhadora é cada vez mais subjugada ao capital, sofrendo, nestes termos, a negação ampla da condição de sujeitos revolucionários. Tomamos como referencial teórico-metodológico do presente ensaio a crítica onto-marxista ao sistema sociometabólico do capital. Quanto ao estudo sobre a crise estrutural do capital recorremos às formulações de István Mészáros. Constatamos que as profundas mudanças que ocorrem no processo de crise do capital estão vinculadas ao complexo do trabalho, produzindo efeitos sobre a realidade da educação. Trata-se, portanto, aqui de uma reflexão mais descritiva e exploratória, com o objetivo de explicitar a relação entre este contexto de crise, as demandas endereçadas à educação e seu lugar neste processo, destacando limites e possibilidades.

PALAVRAS-CHAVE: Crise estrutural do capital. Educação. Trabalho.

ABSTRACT: At the current moment of structural crisis of capital, in which the productive forces are also reconfigu-red in the form of destructive production, the working class is increasingly subjugated to capital, suffering, in these terms, the widespread denial of the condition of revolutionary subjects. We take as theoretical and methodological reference of this essay the onto-Marxist critique of the capital's social-metabolic system. Regarding the study about the structural crisis of capital, we use the István Mészáros formulations. We note that the profound changes taking place in the capital crisis process are linked to the labor complex, producing effects over the reality of education. This article concerns, therefore, about a descriptive and exploratory reflection, with the goal of show the relationship between this crisis context, the demands regarded to education and their role in this process, highlighting limits and possibilities.

KEYWORDS: Structural crisis of capital. Education. Labor.

RESUMEN: En el actual momento de la crisis estructural del capital en que las fuerzas productivas se reconfiguran en la forma de producción destructiva, la clase trabajadora es cada vez más subyugada al capital, sufriendo, en estos termos, la negación amplia de la condición de sujetos revolucionarios. Tomamos como marco teórico y metodológico del presente ensayo, la crítica onto-marxista al sistema socio-metabólico del capital. Cuanto al estudio acerca de la crisis estructural del capital recorrimos a las formulaciones de István Mészáros. Percibimos que los profundos cambios que ocurren en el proceso de crisis del capital están vinculados al complejo del trabajo, produciendo efectos sobre la realidad de la educación. Es, por tanto, una reflexión más descriptiva y exploratoria, en orden de aclarar la relación entre este contexto de crisis, las demandas dirigidas a la educación y su lugar en este proceso, poniendo de relieve los límites y posibilidades.

PALABRAS CLAVE: Crisis estructural del capital. Educación. Trabajo.

Artigo recebido em janeiro de 2016

Aprovado em março de 2016 


\section{1| INTRODUÇÃO}

O atual contexto da crise estrutural do capital é caracterizado pela determinação da produção destrutiva e precarização do trabalho, o que proporciona uma consequente reconfiguração dos demais complexos sociais. Tomamos como referencial teórico-metodológico do nosso estudo a crítica marxista ao sistema sociometabólico do capital para explicar, em linhas gerais, as reformas e políticas de cunho paliativo, voltados à administração da crise. Nelas, o capital, sob a égide do Estado, vem delegando à educação a função social de formação para a cidadania e para o mercado de trabalho que, em seus termos, contribuiria para a materialização das relações democráticas e de desenvolvimento nos moldes da sociedade atual.

Para Harvey (1994), o único ponto de consenso entre os inúmeros teóricos que vêm estudando as transformações da realidade produtiva nos últimos anos é que algo muito significativo ocorreu a partir dos 1970. O elemento central da discussão, porém, entre os marxistas, é saber o que representa para a sociedade capitalista atual estas tão expressivas mudanças, especialmente na educação e na formação do trabalhador, em meio aos desdobramentos da crise do capital.

Tradicionalmente, a sociologia contemporânea, com base no marxismo, tem identificado o processo de transformação no sistema do capital como uma resposta às crises cíclicas inerentes ao seu modo de funcionamento e não como resultado causal e natural da evolução da sociedade. A crise estrutural do capital, por sua vez, pode ser definida, em linhas gerais, como uma fratura nos princípios e fundamentos que marcam o modo de funcionamento da sociedade capitalista de produção. Para Marx (1989), as causas da crise no sistema do capital devem ser buscadas nas condições de acumulação do sistema capitalista de produção, cuja lei básica resulta no movimento decrescente das taxas de lucros. Tal tendência está associada ao avanço das forças produtivas combinada com a irracionalidade própria da concorrência entre os capitais, mesmo que possa, eventualmente, ser em parte contrabalançada pela atuação do Estado.

Nesse sentido, o autor acrescenta que a razão dessa tendência é o crescimento contínuo da produtividade do trabalho. Na corrida pela reversão da queda da taxa de lucros, os capitalistas investem em tecnologia e matéria-prima para aumentar a produtividade, elevando, desse modo, a composição orgânica do capital, ou seja, o crescimento do capital constante em relação ao capital variável, provocando, por esta via, o efeito contrário ao esperado: a diminuição das taxas de lucros, dado que a fonte da mais-valia é a força de trabalho - o elemento central do capital variável que foi rebaixado pelo acréscimo do capital constante. Conforme Marx (1989), os capitalistas buscam a maior produtividade porque, em curto prazo, adquiririam um benefício significativo, obtendo elevados lucros, uma vez que possuiriam, com exclusividade, novas tecnologias para produzir e vender com preços acima dos demais concorrentes até que o mercado seja inundado pela mesma tecnologia, barateando todos os produtos.

Nessa direção, a taxa de lucro não cai porque o trabalho se torna menos produtivo, mas o contrário, porque este se torna mais produtivo. A tendência à queda da taxa de lucro é, portanto, um reflexo das próprias leis contraditórias do capital que, com o crescimento da produtividade, promove a saturação de produção no mercado, tornando-se uma barreira intransponível para o próprio capital, que passa a destruir as forças produtivas para que o lucro volte a crescer. Esse movimento é sempre orientado para a finalidade do processo de acumulação ampliada do capital.

Marx (1989) rejeitava qualquer relação causal entre as crises econômicas e os aumentos salariais conquistados pelos trabalhadores ou em decorrência da luta dos sindicatos por melhores rendimentos para a classe trabalhadora. Ele considerava as crises soluções momentâneas e violentas das próprias contradições existentes no capitalismo que restaurariam, transitoriamente, o equilíbrio desfeito no processo de acumulação do capital. 
Do mesmo modo, em O Capital (MARX, 1989) discute as estratégias que o sistema se utiliza para contrabalancear a tendência decrescente das taxas de lucros inerente à lógica do processo de acumulação ampliada do capital, as chamadas contratendências, tais como: o aumento da taxa de exploração do trabalho, a diminuição dos salários, a redução de custos com capital constante, a valorização do comércio exterior, entre outros.

Pesquisas mais recentes como a de Mészáros (2002) apontam outras estratégias utilizadas pelo capital com esse mesmo fim, tais como: a produção descartável e a produção destrutiva, esta última característica do complexo industrial militar. Todos esses artifícios têm forte repercussão no mundo do trabalho e sobre a formação do trabalhador. Iniciaremos a discussão com a contribuição de Mészáros (2002) para, então, visualizar os efeitos da crise no mundo do trabalho, a partir de uma revisão narrativa da literatura, tomando como critério de escolha a relevância das contribuições de diversos pesquisadores que vêm debatendo essa questão no escopo da sociologia do trabalho e da educação. Trata-se, portanto, de uma reflexão mais descritiva e exploratória, com o objetivo de explicitar a relação entre este contexto de crise do capital, o mundo do trabalho e as demandas endereçadas à educação.

\section{2 | A TESE DE MÉSZÁROS E SUA CONTRIBUIÇÃO PARA PENSAR A CRISE DO CAPITAL}

É importante distinguir, didaticamente, embora na prática as crises do capital se encontrem estreitamente associadas, as crises conjunturais, ou colapsos parciais, da crise geral ou estrutural que atinge os princípios organizativos do sistema social e conduzem a certas mudanças na orientação produtiva da sociedade capitalista. As crises parciais estão associadas aos ciclos econômicos e elas são as faces mais visíveis do sistema capitalista de produção: elas envolvem surtos de crescimento e prosperidade aparentemente ilimitados acompanhados de declínio da atividade econômica e de "queima" de capital.

Já a crise estrutural resulta naquilo que Mészáros (2002) denominou "ativação dos limites absolutos do capital", em que os limiares intrínsecos ou absolutos do sistema foram atingidos e não podem ser transcendidos sem a transformação de seus pressupostos básicos, ou seja, sem que seu modo de funcionamento e controle seja qualitativamente alterado. A crise estrutural, para Foster (2011), está associada à nova fase do capitalismo - o monopólio financeiro do capital. Para ele este período se caracteriza pela estagnação econômica nas economias capitalistas maduras; pela mudança dramática para a financeirização, ou seja, bolhas especulativas, como meio de expansão econômica; e a concentração rápida (e monopolização) do capital em escala global.

O quadro de "incontrolabilidade" que caracteriza o movimento do capital dá provas inequívocas de que o contexto atual ativou os limites estruturais do sistema do capital, evidenciando uma crise crônica e profunda, cujo desfecho para a história da humanidade é totalmente imprevisível. É neste sentido que o sistema do capital fará uso de todas as "armas" e subterfúgios para adiar esse momento, no entanto os limites destas estratégias tendem a se reduzir com o agravamento da crise estrutural do capital.

Dessa forma, o capital legitima o chamado complexo industrial militar, como um desses subterfúgios de enfrentamento da crise, que passa, nessa quadra histórica, a representar efetivamente, uma das mais poderosas formas de deslocar as suas contradições e alavancar o seu processo de acumulação demonstrada pela incontrolabilidade do sistema, pondo em risco não apenas a humanidade, mas a sua a própria viabilidade societal.

Assim sendo, o capital, como meio de expansão econômica, derruba os obstáculos impostos pelo consumo real, através da forte intervenção do Estado moderno na compra de artefatos bélicos, 
além de beneficiar os interesses do capital rentista privado e das grandes empresas de armamentos, dando suporte ao movimento do predomínio do capital parasitário e da concentração e centralização do mesmo. Entretanto, ao tentar criar um artifício que beneficie um processo de acumulação sem entraves, acaba por trazer a possibilidade da destruição do seu próprio sistema sóciometabólico.

De acordo com Mészáros (1998), portanto, a crise estrutural do capital representa a séria manifestação do encontro do sistema com seus limites, inerentes ao seu funcionamento. Ele explica que a ativação dos limites absolutos do capital não está separada, mas, ao contrário, tende desde o início a ser inerente à lei do valor, correspondendo à plena maturidade dessa lei, no contexto do encerramento da fase de ascendência histórica do capital. Por outro lado, é possível afirmar, segundo ele, que essa fase de ascendência teve o seu fim decretado porque o sistema do capital atingiu os seus limites absolutos no que se refere à acomodação da lei do valor a seus limites sistêmicos. Nesta perspectiva, o germe dessa crise estaria contido em suas contradições, agravadas pelo atual estágio capitalista. Essas contradições exigem o uso mais intensivo de estratégias de produção destrutiva, que são deslocadas temporariamente e que, até o presente momento, operam com significativo sucesso, antes de ocorrer o esgotamento da sua efetividade (MÉSZÁROS, 2012).

Assim sendo, o capital se apoia em uma "rede articulada de contradições" que consegue administrar de forma parcial por um período de tempo determinado, mas que não pode superar definitivamente. A raiz dessa rede estaria situada na contradição fundamental entre capital e trabalho. Segundo Jessop (2013), no contexto de crise, o processo de acumulação ampliada do capital acirra a exploração do trabalho, desconsiderando qualquer medida humana como norte do processo produtivo; transformando, nesse propósito, as potencialidades produtivas do homem de atendimento as suas necessidades para a produção da destruição, impossibilitando, nestes termos, qualquer controle sobre as tendências destrutivas derivadas da dominação da qualidade pela expansão quantitativa.

A quantificação atinge todas as instâncias sociais sob os ditames do capital e traz consequências para o exercício do trabalho vivo, que se torna mecânico e mensurável, desconsiderando a dimensão humana (qualitativa) do trabalhador. Ao mesmo tempo, à medida que o capitalismo atinge o seu estágio mais avançado, trazendo profundas transformações no processo produtivo derivadas da revolução técnico-científica, cresce a utilização dos setores não produtivos e parasitários frente ao trabalho produtivo. Em outras palavras, diminui-se a utilização do trabalho vivo, elevando absurdamente a composição orgânica do capital, o que resulta no desemprego estrutural e na crescente precarização, tanto da atividade laborativa como das condições de vida do trabalhador. A contradição entre o trabalho produtivo e não produtivo advém da contradição fundamental entre capital e trabalho e do caráter explorador do trabalho no capitalismo, que necessita de uma forma de controle adequada para manter a exploração e a subjugação da força de trabalho.

A transformação da atividade humana livre e consciente em uma mercadoria tornou possível a existência de um controle do capital sobre as jornadas de trabalho, exercido de forma horizontal e vertical, de acordo com os parâmetros da divisão de trabalho capitalista. A dimensão horizontal se refere à divisão funcional do trabalho, que, por sua vez, é inseparável da dimensão vertical que corresponde à estrutura de comando do capital, cujo objetivo reside em salvaguardar os interesses ligados à vitalidade do sistema, ou seja, assegurar a extração de mais-valia conjugada a máxima exploração do trabalho.

Centrando nosso estudo nas crises do capital, do final do século $X X$ até a atualidade, podemos destacar a eclosão da crise na década de 1970 (mais precisamente 1973-1974), que acarretou um esgotamento do padrão de acumulação fordista/taylorista e de sua base estatal keynesiana, que nos anos anteriores trouxera altas taxas de crescimento econômico, sem, contudo, eliminar 
as crises cíclicas, o que fez com que alguns historiadores denominassem esse período de "anos dourados" ou os "trinta anos gloriosos".

Como resposta ao desmantelamento do modelo anterior e a consequente queda das taxas de lucro, o capital, personificado na burguesia, conduziu uma ofensiva, pautada na reestruturação econômica e político-ideológica, como base na desregulamentação (tanto dos processos comerciais, como das operações financeiras); a flexibilização das relações de trabalho e da produção e a privatização do patrimônio público. Tais medidas foram expressas em um tripé fortemente articulado: a reestruturação produtiva (com a implantação do toyotismo como modelo de organização e gerenciamento da produção), o ideário neoliberal e a financeirização (PAULO NETTO; BRAZ, 2007; PAULO NETTO, 2010).

A reestruturação produtiva, concretizada, em especial, pela implantação do toyotismo, provocou profundas mudanças no setor produtivo, além de exigir um trabalhador polivalente, capaz de executar inúmeras funções no manuseio das novas tecnologias, que, por sua vez, resultou na diminuição do trabalho vivo e o aumento do número de trabalhadores no setor dos serviços (setor predominantemente parasitário). Essa nova configuração gerou fortes implicações para o conjunto dos trabalhadores, destacando-se a precarização do trabalho e o desemprego em massa, que na atual conjuntura assume um viés estrutural. Paulo Netto e Braz (2007) pontuam que a diminuição da quantidade de trabalhadores no setor produtivo e o aumento do setor de serviços fornecem o suporte fenomênico para a legitimação das teorias do fim do trabalho.

Valendo-nos da tese de Foster e Mészáros (2008), situamos que o debate sobre a crise do emprego e suas consequências para a inserção dos jovens no mundo do trabalho tem que ser refe- rendado nos termos da própria crise do capital. A proximidade desta discussão com as questões atuais da educação brasileira justifica-se porque, em tese, nos discursos governamentais a reforma educacional é colocada como a resposta necessária às modificações que vêm ocorrendo na base produtiva da sociedade e no mercado de trabalho. Diante destas mudanças, são exigidas novas qualificações do trabalhador, de modo a garantir à força de trabalho uma constante "empregabilidade". Aliás, este conceito ganhou grande visibilidade a partir dos anos de 1990, com a ascensão das ideias neoliberais e pós-modernas que se tornaram hegemônicas no Brasil. Corresponderia à concretização, na prática, do fim das relações estáveis de assalariamento, substituídas por relações flexíveis de trabalho por tarefa, produto, projeto ou missão. A referência do emprego deixa de ser o contrato fixo baseado no pagamento de salário por uma determinada jornada de trabalho e passa a ser guiada por contratos flexíveis, sem vínculos de emprego fixo entre patrões e empregados.

Neste cenário, cabe ao próprio trabalhador investir permanentemente na sua formação para o trabalho a fim de garantir sua empregabilidade, visto que o mundo da produção está passando por mudanças igualmente constantes e compete ao trabalhador se preparar e a elas se adaptar. Assim, passa-se a creditar à educação um papel central na reconversão tecnológica, na melhoria do capital humano e na equalização social (LANZI, 2007).

De fato, na prática, não foram encontradas nos limites do sistema do capital, estratégias de resistência e superação das dramáticas consequências sobre a força de trabalho do avanço e do uso intensivo e quase indiscriminado das novas tecnologias, inclusive da informação, acoplada ao processo de desregulamentação do mercado de trabalho promovido pelo avanço do ideário neoliberal e pela globalização das forças do capital, até porque não podem ser encontradas dentro destas fronteiras.

Nessa direção, no contexto do pensamento dominante vinculado aos interesses do sistema do capital, destacam-se, em nossa compreensão, três grandes teses que procuram explicitar as causas do fenômeno do desemprego e sua relação com o processo de formação para o trabalho, 
incluindo a escolarização: a tese da globalização, a da reestruturação produtiva e a da desqualificação da força de trabalho. No entanto, no interior de cada tese, as posições dos vários estudiosos não são homogêneas com destaque para divergências quanto à natureza deste fenômeno. A discussão é ampla e profunda com leituras as mais dissonantes, em várias áreas das ciências humanas.

Para alguns teóricos da sociologia da educação e do trabalho, inspirados na tradição marxista, tais como Frigotto (1994) e Antunes (1999), o desemprego atual reflete um fenômeno estrutural, expressão de uma necessidade do capital em crise profunda. Já para outros teóricos e pesquisadores desta área trata-se de um fenômeno apenas conjuntural, que não compromete, em essência, o modo de funcionamento atual de nossa sociedade; nesta linha destacam-se Paiva (1991), Mello (1999) e Castro (1997).

Numa tentativa de inter-relacionar as três teses, buscou-se estabelecer uma articulação entre elas e o clássico conceito marxista de Exército Industrial de Reserva (EIR), apoiando-se na descrição mais precisa que, na atualidade, Mészáros (2002) faz desta categoria. Nesse sentido, o estudo aqui proposto tem caráter mais descritivo e exploratório, com o objetivo de explicitar a relação entre este contexto de crise do capital, o mercado, o trabalho e o lugar da educação neste processo.

\section{3 | GLOBALIZAÇÃO, DESEMPREGO E QUALIFICAÇÃO PARA O TRABALHO}

A primeira tese sobre o desemprego aponta a globalização recente como a grande causa de sua explosão nas suas dimensões atualmente verificadas. Embora não seja um fato recente, as características da chamada globalização contemporânea (em contraposição, por exemplo, à existente no império inglês do final do século XIX) permitem descrevê-la como um fenômeno estreitamente associado ao extraordinário desenvolvimento do moderno sistema capitalista de produção. A maior liberalização da economia, a abertura ampla dos mercados e a desregulamentação financeira têm favorecido as economias mais desenvolvidas. As desigualdades no mundo estão se ampliando, assim como a concentração de capitais. Tal realidade tem repercussões claras na divisão mundial da força de trabalho. Para alguns autores como Chesnais (1996), a marca da globalização atual, por ele denominada mundialização tendo em vista sua perspectiva teórica, é a "financeirização" da economia, ou seja, o domínio da atividade de intermediação de capital sobre a atividade propriamente produtiva.

A globalização atual exibe dois efeitos centrais: se por um lado maximiza as oportunidades do capital em função de sua mobilidade, por outro a "financeirização" crescente de grande massa de capitais e o avanço tecnológico parecem apontar para uma implosiva crise de superprodução e superacumulação. Fatos como a instabilidade nas bolsas de valores, a crise asiática dos anos 1990 e mais recentemente a "exuberância irracional" das ações no mercado americano e a explosão dessa bolha especulativa, em 2008, assim como a crise da dívida de alguns países da União Europeia, seriam sintomas desta crise.

Vale ressaltar, porém, que o processo da chamada globalização não se restringe apenas ao aspecto financeiro, mas vem atingindo o próprio processo de produção como demonstra a transferência de plantas industriais inteiras para países menos desenvolvidos e de mão de obra mais barata como a China (CHESNAIS, 1996). A ideologia da globalização também tem provocado uma série de mudanças importantes na distribuição internacional de trabalho, com fortes impactos sobre o emprego. O processo de desregulamentação do trabalho, intensificado pela globalização, tem penalizado de forma severa as economias de base industrial e tecnológicas frágeis e mais dependentes como a brasileira, aumentando as desigualdades e precarizando ainda mais a força de trabalho. 
O efeito da proclamada globalização não é uniforme sobre a economia mundial. Inúmeros fatores podem afetar suas consequências, dentre os quais se destacam o tipo de inserção de cada país no mercado globalizado. É evidente que uma política de abertura comercial indiscriminada pode resultar em uma "importação de empregos". A questão não é, porém, o grau de abertura comercial que faz um país, mas é mais ampla, pois diz respeito à forma como cada país se insere no mundo globalizado e seu "poder de fogo" na competição intercapitalista. Como os efeitos não são homogêneos, pois não existe uma economia planetária em concorrência perfeita, é logicamente insuficiente atribuir apenas à globalização as causas do desemprego, em especial nos países centrais, maiores beneficiários do fenômeno.

\section{4 | REESTRUTURAÇÃO PRODUTIVA, DESEMPREGO E FORMAÇÃO PARA O TRABALHO}

O avanço tecnológico extraordinário e a reestruturação produtiva observada, em especial, no século $X X$, são considerados por muitos teóricos como os grandes responsáveis pelo declínio inevitável dos níveis de emprego na economia mundial. A introdução de novas tecnologias, de novas máquinas, da informática, da automação e da robótica no processo produtivo provocou uma verdadeira revolução na produtividade do trabalho e, como consequência direta, um forte impacto sobre os níveis de emprego.

Marx (1989), ao analisar as consequências do avanço tecnológico nos Grundrisse, avaliou este movimento como inerente à própria lógica do sistema capitalista de produção. Para ele, o capital tenderia a aumentar as forças produtivas, ao mesmo tempo em que diminuiria ao máximo o trabalho vinculado. Esta orientação de revolucionar constantemente os meios de produção atinge o seu auge no desenvolvimento da grande indústria em que o trabalho objetivado na forma de capital fixo se apropria do trabalho vivo e o domina ativamente no processo de produção real.

Como consequência imediata deste movimento, o trabalho direto e necessário perde cada vez mais sua expressão quando comparado ao poder e a força da maquinaria (MARX, 1989). O avanço tecnológico produz, assim, três impactos importantes sobre o processo produtivo: o aumento da produtividade do trabalho; a diminuição do trabalho vivo direto e necessário e a promoção da ciência como a principal força produtiva. Na produção em série, típica da maquinaria, é eliminada a relação direta entre o produtor e o produto, logo o valor de uso imediato da força de trabalho é progressivamente eliminado.

Por sua vez, o trabalho objetivado na maquinaria não é um simples instrumento de trabalho, mas se transforma pouco a pouco na própria força produtiva e na própria face do capital. Significa a transformação dos meios de trabalho tradicionais em meios adequados à produção do valor. Neste sentido provocam-se diversas acumulações no capital que se opõem ao trabalho: de saber, da habilidade e de todas as forças produtivas (MARX, 1989). É por isso que a ciência se torna, a partir de então, numa propriedade do capital, do capital fixo, pois entra no processo de trabalho como produção efetiva.

Neste quadro, o processo produtivo vai se tornando cada vez mais independente da habilidade do trabalhador e mais dependente da aplicação tecnológica e da ciência. No entanto, é o próprio desenvolvimento das forças produtivas que ativa a contradição central do sistema do capital e que pode operar sua possível dissolução: pois no capitalismo o tempo de trabalho, simples quantidade de trabalho, é o único princípio determinante para a criação de mais valor. Ora, se o trabalho imediato deixou de ser o elemento determinante da produção e da criação de valores de uso ele é dispensável? Se seu papel agora é ínfimo e subalterno à tecnologia e atividade científica e à organização social, sua centralidade é eliminável? 
Eis o problema. O capital fixo, as máquinas e os autômatos podem produzir riqueza enquanto valores de uso, mas não podem transmitir aos meios de produção mais valor sem a presença do trabalho humano. O capital fixo só pode imprimir ao produto o trabalho objetivado nele contido e não valor novo. No entanto, o mais valor pode ser obtido pelo aumento da taxa de sobretrabalho em relação ao trabalho necessário. Neste sentido, a introdução de novas máquinas não pode resultar em menos trabalho para os trabalhadores que permanecem no emprego, mas ao contrário, resultará numa intensificação e piores condições no processo de trabalho. Ou seja, como o sistema precisa submeter toda a produção à lógica do valor, o resultado do trabalho obtido é superior ao trabalho necessário, podendo gerar uma superprodução. Esta última, por sua vez, produzirá na esfera da circulação a queda tendencial nas taxas de lucro e, logicamente, a crise no sistema do capital.

Tal fato se concretiza porque a taxa de lucro é uma relação entre a taxa de exploração do trabalho (taxa de mais valia) e os meios utilizados no processo produtivo ou composição orgânica do capital. Se tal composição aumenta em função do aumento do capital fixo numa proporção maior do que o capital variável ali empregado, a taxa de mais valia a ele diretamente ligada tem que subir em igual proporção. Quanto maior é a composição orgânica do capital, maior deverá ser a taxa de exploração (ROSDOLSKY, 2001). Em outras palavras, quanto maior é o capital fixo empregado maior deverá ser a taxa de mais valia ou de sobretrabalho para que a taxa de lucro não seja comprometida. Neste sentido, encerra-se uma contradição, uma vez que o capital, ao fomentar o desenvolvimento das forças produtivas e o consequente atingimento de certo ponto da produção, proporciona a anulação de sua autovalorização em vez de propiciá-la (MARX, 1989).

Em síntese, para Marx é ilusão supor que o avanço tecnológico levará à diminuição do tempo de trabalho e torná-lo mais fácil. Ao contrário, a introdução de novas máquinas ocorre exatamente quando há força de trabalho em excesso, pois a simplificação do trabalho produzida pela maquinaria e aparelhos tecnológicos (FLUSSER, 2011) permitirá a necessária exploração do sobretrabalho dos trabalhadores que são aproveitados no processo produtivo. É óbvio que o processo só ganha esta direção porque capitaneado pela lógica do capital que submete as forças da ciência, da natureza e o tempo de trabalho necessário à bitola estreita da valorização do valor.

Este quadro demonstra, assim, que é um erro considerar a reestruturação produtiva como resultante de um anônimo, irreversível determinismo tecnológico a partir do qual o desemprego é apenas uma consequência indesejável. É básico considerar, igualmente, a luta de classes: pelo lado das elites a reconversão produtiva tem sido utilizada econômica e politicamente para acuar a classe trabalhadora, alimentar a produção desnecessária e manter intacto o atual sistema de acumulação, bloqueando, inclusive, todas as iniciativas que beneficiem a classe trabalhadora e a sociedade com o desenvolvimento das forças produtivas; pelo lado dos trabalhadores o questionamento e a resistência ao avanço tecnológico não são simplesmente passivos e de adaptação às imposições do capital, mas existem forças sociais organizadas que continuam lutando para romper com a lógica do valor.

\section{5 | DESQUALIFICAÇÃO DA FORÇA DE TRABALHO: DESAFIO PARA O EMPREGO E A EDU- CAÇÃO?}

A terceira tese que objetiva explicar o desemprego é a da desqualificação da força de trabalho. Trata-se, na verdade, de um discurso ideológico cujo fim central é inverter a causa pelo efeito, culpabilizando e penalizando os trabalhadores pela própria crise do sistema do capital. No caso específico do Brasil tem sido corrente a fala do governo e do empresariado que as taxas de desemprego no país podem ser explicadas, em parte, pela baixa qualificação da população, tendo 
em vista, por exemplo, a baixa qualidade da educação recebida pelo trabalhador. Em alguns setores, haveria disponibilidade de empregos ou se faz necessária a contratação de trabalhadores de outras regiões ou até de outros países, visto que faltaria ao trabalhador a qualificação exigida pelo capital. Assim, os indicadores educacionais, em particular, das regiões Norte e Nordeste, parecem corroborar com esta afirmação, visto que a maioria destas populações possui no máximo até quatro anos de escolaridade formal (IBGE, 2004). No entanto, mesmo em países desenvolvidos a maior parte dos empregos é ainda de perfil de baixa tecnologia, equivalente, no nosso caso, ao ensino médio ou ao ensino técnico profissionalizante (DE NEGRI; DE NEGRI; COELHO, 2006).

Mesmo que se considere o ponto de vista do sistema do capital e do mercado, restaria, então, o seguinte dilema: se o problema é de qualificação, porque mesmo os trabalhadores qualificados ficam desempregados? Ou ainda, se todos os trabalhadores fossem qualificados ou mesmo requalificados, haveria emprego para todos? Como é possível para o mercado ter clareza do tipo de qualificação que ele quer se este mercado está em constante mutação? Qual o ponto ótimo entre um trabalhador genericamente qualificado, flexível e empregável e as necessidades específicas das empresas? Além do que uma educação para o mercado de trabalho não significa e, na maior parte das vezes não é o que ocorre, uma educação para o trabalho, em que o último corresponde a uma dimensão fundante e constitutiva de todo ser humano (MAIA FILHO, 2011).

Há, portanto, muitas dúvidas, embora não se possa desconsiderar de nenhuma forma o núcleo do raciocínio: de fato um dos problemas sérios do país, que limita sua competitividade e produtividade, pelo menos na perspectiva intercapitalista, é a baixa qualificação de sua força de trabalho, no entanto é limitado considerá-la isoladamente como a causa central do desemprego, da crise econômica e da educação. Aliás, se os índices oficiais de desemprego no país não considerassem os trabalhadores informais e de baixa qualificação como "empregados" não seriam publicados, de tão alarmantes.

As três grandes teses que procuram explicar o desemprego, aqui rapidamente expostas, podem levar a análise a assumir um risco ainda maior: o de um determinismo natural e mecânico do qual não há saída possível. Este processo de naturalização das causas dos fenômenos é particularmente visível na análise da reestruturação produtiva. Diante da crise do capitalismo atual, o capital tende a investir maciçamente na introdução de novas tecnologias (capital fixo), que por sua própria natureza são poupadoras de força de trabalho, fato que tende a tornar o desemprego cada vez mais irreversível e mais grave. Rifkin (1995), cujo título do livro já coloca claramente os termos da questão - "O Fim dos Empregos: o declínio inevitável dos níveis de emprego e a redução da força global de trabalho" -, parece não ver outra saída para a questão das novas tecnologias senão pelo deslocamento da força de trabalho para o terceiro setor da economia através de um novo pacto entre o capital e o trabalho, independentemente do que se possa fazer em termos de qualificação para o trabalho, inclusive através da escolarização. Destaque-se que o terceiro setor não se restringe à área de serviços, mas corresponderia ao trabalho social do governo e das organizações (trabalho voluntário e serviços comunitários devidamente "remunerados").

À naturalização da tese do declínio inevitável dos níveis de emprego em função da reestruturação produtiva, as análises atuais colam automaticamente e de forma naturalizadora uma segunda tese: a reestruturação não só tem exigido novas qualificações da força de trabalho como também tem produzido uma diferenciação crescente (heterogeneidade) no seio da classe trabalhadora através da diminuição galopante do operariado fabril, da diminuição dos empregos estáveis, do aumento do trabalho informal e crescimento do setor de serviços, entre outros fatos do mundo do trabalho (HARVEY, 1994).

Tal realidade explicaria vários fatos atuais: a crise do movimento sindical, o arrefecimento da luta de classes e até mesmo, no extremo, a perda da centralidade do trabalho como condição 
básica de sobrevivência e na determinação da identidade do sujeito. Este quadro teria sido agravado pela globalização que tem possibilitado a aceleração dos ciclos do capital, a expansão das novas tecnologias para regiões "virgens", inclusive as novas tecnologias da comunicação, a financeirização da economia, entre outros fenômenos.

Meneleu Neto (1996), em contraposição às teses "naturalistas" e às determinações mecânicas da reestruturação produtiva, do fim da centralidade do trabalho e da globalização, argumenta, corretamente, que tais teses não colocam em relevo os principais sujeitos da ação (na verdade, sujeitos assujeitados) no sistema capitalista de produção, o capital e o trabalho, na forma histórica e dinâmica da luta de classes, em termos da configuração que ela assume nos dias de hoje. Antes de representarem a negação desta luta, ou a expressão da superação do conflito, os fatos da crise apontam, ao contrário, para um acirramento do conflito, portanto para um aumento na tensão na luta de classes nas relações de produção.

O aumento do desemprego e, portanto, do EIR, após a crise do Estado de Bem-Estar Social europeu e americano (Welfare State) nos anos 1970, teria sido uma vingança do mercado contra as políticas econômicas keynesianas que marcaram aquele período, incluindo a melhoria da qualificação do trabalhador e de sua escolarização? A realidade, mais forte que tais políticas, teria ressuscitado o "desemprego necessário" e a "taxa natural de desemprego"? Ou teria sido o resultado deliberado das políticas econômicas neoliberais de desregulamentação do trabalho que dominou os estados-nações a partir daquele período? Antes de ser uma consequência, o aumento do EIR pode ser, de fato, a causa que explica ou esclarece melhor muitas das teses que explicam a crise atual, argumenta Meneleu Neto (1996). Até porque a naturalização da tese do determinismo tecnológico não é um dado inocente, visto que o sistema permanece capitalista, logo se mantém o conflito entre o capital e o trabalho a ele inerente, a luta de classes que o movimenta.

O reforço desta ideologia do determinismo tecnológico coincide com as transformações econômicas e sociais que, no cenário desta luta entre classes, foram acionadas pelos sujeitos da ação do sistema do capital para fazer frente a crise dos anos 1970: implosão do modelo taylorista-fordista keynesiano de regulação e acumulação; aumento na concorrência intercapitalista; queda progressiva nas taxas de lucro; superprodução e superacumulação e financeirização da economia, entre outros fatores. Deste modo, defende Meneleu Neto (1996), se as recentes modificações na base do sistema capitalista acarretaram, entre outros efeitos, o aumento do desemprego, logo é fundamental analisar de modo mais profundo os nexos entre o desemprego, a crise do capital e as políticas neoliberais que vêm acompanhando o metabolismo do sistema nos últimos trinta anos e seus impactos na formação do trabalhador.

Do ponto de vista marxista, a manipulação do EIR foi a grande arma utilizada pelo capital, em especial no século $X X$, para regular o salário dos trabalhadores. A expansão do EIR tinha como objetivo direto a obtenção da queda dos salários reais dos trabalhadores. Essa contração coincidia com a expansão da própria atividade capitalista e só então poderia levar a um novo aumento dos salários reais. No entanto, o tamanho do EIR não é função apenas dos movimentos do mercado e da determinação do capital: ao contrário, seu verdadeiro motor é a luta de classe e não os automatismos do mercado. Além disso, é necessário considerar o importante papel exercido pelo Estado moderno nesse contexto.

O quadro da crise hodierna do capital, que vem se verificando nos últimos trinta anos, está no centro dos debates atuais e já foi amplamente descrito por inúmeros analistas, mas parece haver pouco consenso quanto a algumas de suas determinações mais gerais. No plano econômico emerge uma profunda crise no modelo keynesiano taylorista-fordista de regulação, com o surgimento de novas formas de gestão da produção como o toyotismo japonês; aumento da concorrência intercapitalista; introdução de novas tecnologias na produção e financeirização da economia. 
No plano político e econômico ressurgem com força as políticas monetaristas de controle da inflação e suas ligações com o sistema financeiro, decorrente da ascensão do ideário neoliberal.

A reação do Estado e do grande capital só poderia estar, desta forma, associada a sintomas mais profundos: a crise do modelo fordista é, na verdade, uma crise de rentabilidade, de queda crescente na taxa de lucro das corporações; a crise do Estado e sua política de controle da inflação denunciam os limites da ação econômica do Estado nos marcos do capitalismo (capacidade de endividamento, de controle monetário e fiscal e de provimento de bens sociais); a crise na educação demonstra os paradoxismos de uma formação voltada para o mercado em constante mutação.

Ora, é exatamente nos anos setenta do século passado que o modo de regulação fordista começa a ter problemas e a minar a tão bem-sucedida "tríplice aliança": estagnação ou queda nos salários reais pelo lado dos trabalhadores; um forte endividamento por parte do Estado intervencionista e queda mais acentuada na taxa de lucros dos capitais; aprofundamento das desigualdades e da divisão internacional do trabalho.

Desta forma, a crise de valorização do capital e o colapso do padrão de acumulação fordista/ keynesiano, aliado a desregulamentação e a liberalização da economia, abriram as portas para um regime de acumulação derivado de outro estágio do processo de internacionalização. Essa nova fase de desenvolvimento capitalista, que reflete um estágio particular do imperialismo atual, foi denominada por Chesnais de mundialização do capital (CHESNAIS, 1996, 2001; DUMENIL et al., 2003) ou expansão mundial do capital, no contraponto a uma globalização sistêmica e espontânea. Chesnais (1996, p. 15) afirma que o verdadeiro conteúdo da globalização consiste na mundialização das operações do capital (tanto no que se refere aos investimentos no setor produtivo como no setor financeiro) e não na mundialização das relações de troca; para ele "a economia 'globalizada' é excludente, pois é dirigida pelo movimento do capital e nada mais."

Mészáros (2008) alerta que por ter um caráter estrutural a crise ora vivenciada tende a se agravar, atingindo não apenas o setor financeiro global, predominantemente parasitário, mas todos os campos sociais, econômicos, culturais e políticos. Pode-se dizer que já é possível perceber alguns desdobramentos desse aprofundamento, através da degradação ambiental; do aumento da violência (que se estende da cidade ao campo); da precarização cada vez maior das condições de trabalho; da miséria absoluta de milhares de pessoas; da mercantilização dos processos educativos e da programação da vida acentuada pelo uso dos aparelhos computacionais. Toda essa situação se intensifica com as constantes crises econômicas, incluindo a atual crise europeia que atinge a economia global e produz efeitos danosos para o proletariado, através de medidas de austeridade fiscal impostas por agências multilaterais ou grupos de países (a exemplo da União Europeia) às nações devedoras.

A saída metabólica do sistema do capital, amplamente apoiada pelo Estado, é a de aumentar a composição orgânica do capital pelo investimento maciço em novas tecnologias (controle automático da produção, microeletrônica, robótica, telemática, entre outras); investir em novas formas de gestão da força de trabalho e de recomposição de tarefas, a exemplo do toyotismo japonês, reengenharia americana, lean production alemão; globalizar a produção e o livre movimento financeiro dos capitais; associar o capital produtivo ao financeiro e especulativo; remover o poder sindical pela desregulamentação legal do mercado de trabalho; viabilizar um acesso mais direto ao fundo público através de incentivos diretos e privatização; diminuir o tempo de rotação do capital pela combinação de novas tecnologias, financeirização e movimento livre de capitais (globalização), entre outras saídas como a produção destrutiva, inclusive com uma espécie de pret a porter na produção de saberes "acessíveis" e descartáveis. 
De fato, o modo de regulação taylorista-fordista continha em seu bojo algumas dificuldades para o capital que logo se revelaram: com o passar do tempo o ritmo de acumulação deixou de ser contínuo e começou a perder autonomia, agora preso aos termos da aliança entre o capital, o trabalho e o Estado; a própria relação direta entre o capital, o Estado e o trabalho perdeu autonomia e flexibilidade e o tamanho de EIR deixou de ser determinado pelas "forças de mercado". Deste modo, argumenta Meneleu Neto (1996), o tamanho do EIR deixou de ser determinado pelo movimento autônomo dos capitais e pelas forças de mercado e passou a ser contraditoriamente uma externalidade ao movimento autônomo do capital: enquanto uma política do capital associado ao Estado ela passa a ser o pressuposto e não a consequência da acumulação do capital, numa espécie de reposição invertida do EIR.

Desse modo, políticas monetaristas de controle da inflação (menos inflação e mais desemprego) tem sido a grande tônica das políticas estatais a partir dos anos oitenta do século XX (no Brasil esta configuração aparece com clareza a partir do Plano Real), muitas vezes associadas ao endividamento do estado. Há, portanto, um casamento de intenções políticas, como as políticas neoliberais tão fortes no momento atual, e as determinações diretamente emanadas do contexto da realidade produtiva, onde se observam importantes modificações não só no modo de produzir as mercadorias como na forma de gerir a força de trabalho.

Esta atmosfera político-econômica favorável ao capital torna o controle sobre o ritmo de trabalho ainda mais forte por parte do capital e demonstra, assim, o predomínio da luta de classes no momento político atual, em contraponto a exclusividade das determinações econômicas do EIR a partir do automatismo do mercado. Tal contexto, além de acirrar a luta de classe, coloca sérios questionamentos para o processo educativo: qualificar para o mercado de trabalho não fará da educação e da escolarização senão o movimento ouroboros da cobra que começa a comer o próprio rabo?

\section{6 | CONSIDERAÇÕES FINAIS}

Em nossa compreensão, a proclamada globalização do capital delineou um modo específico de funcionamento do capitalismo contemporâneo, baseado em uma economia cada vez mais concentrada e centralizada por meio de grandes corporações. Além do mais, a inexistência de qualquer barreira protecionista nacional à expansão do capital forneceu também as condições para a dominação do capital financeiro, que a partir de então passa a comandar o processo de reprodução do capital em escala ampliada no contexto de crise estrutural, conforme formula Mészáros (2002).

Com base na teoria do valor de Marx, Chesnais (1996), aborda os dois circuitos de reprodução do capital: um longo e outro curto. O primeiro é gerado no processo de produção de mercadorias no qual dinheiro se transforma em capital, em mais dinheiro. O segundo, não necessita da mediação da produção, ocorre somente na esfera da circulação. O autor enfatiza que sob a égide do regime de dominância financeira tem prevalecido o circuito encurtado, com um deslocamento de recursos para a esfera financeira em detrimento do setor produtivo, o que aumenta a capacidade de realização do capital, mas não aumenta sua valorização.

Há, portanto, uma clara vinculação entre a crise estrutural do capital e o mundo do trabalho seja na forma específica do desemprego ou de uma forma em geral, no modo como os trabalhadores e os futuros trabalhadores são atingidos por esta crise. A crise do sistema do capital, consequentemente, resulta em crise na sociedade e na educação. Não é por acaso que o Estado, enquanto mediador das relações sociais, é chamado, exatamente, para proceder aos ajustes e reformas na sociedade necessários ao seu "equilíbrio". 
De fato, a análise das três grandes teses que procuram explicar o desemprego, expostas ao longo do texto, e sua relação com o mundo do trabalho e a educação do trabalhador, visava denunciar um risco: o de um determinismo natural e mecânico do qual não há saída possível. Este processo de naturalização das causas dos fenômenos é particularmente visível na análise da globalização, da reestruturação produtiva e da formação para o trabalho.

Apoiados em Marx e Mészáros, destacamos que o desemprego é inerente ao modo como o capital operacionaliza sua acumulação. A funcionalidade da reserva de força de trabalho (EIR) é reguladora dos salários, para baixo ou para cima. Em tempos de crise estrutural crônica do capital vivenciamos a barbárie em quase todos os países, mas de forma mais intensa nos mais pobres. Ninguém fica imune à severa desumanização das relações de trabalho, expressada pelo desemprego em massa e a precarização.

Obviamente as profundas mudanças que este processo enseja começam a produzir efeitos sobre a realidade da educação a da escola, locus privilegiado de formação dos sujeitos sociais e dos trabalhadores. Não é casual que sob o controle do Estado, a sociedade e os empresários vêm atribuindo à educação a função de redentora dos males sociais, visto que a escola passaria a ser espaço de formação para a cidadania e para o mercado de trabalho. Lugar por excelência da formação do capital humano, cabe a escola uma função ideológica de que o capital em crise não pode prescindir. 
O PROBLEMA DO MUNDO | Osterne N. M. Filho, Maria das Dores M. Segundo e Josefa Jackline Rabelo

\section{Referências}

ANTUNES, R. Os sentidos do trabalho: ensaio sobre a afirmação e a negação do trabalho. São Paulo: Boitempo, 1999.

CASTRO, C. de M. O secundário: esquecido num desvão de ensino. Brasília, DF: INEP, 1997.

CHESNAIS, F. A mundialização do capital. São Paulo: Xamã, 1996.

Mundialização: o capital financeiro no comando. Revista Outubro, n. 5, p. 7-28, 2001.

DE NEGRI, J. A.; DE NEGRI, F.; COELHO, D. (Org.). Tecnologia, exportação e emprego. Brasília, DF: IPEA, 2006.

DUMENIL, G. et al. Uma nova fase do capitalismo? São Paulo: Xamã, 2003.

FLUSSER, V. Pós-história. São Paulo: Annablume, 2011.

FOSTER, J. B. Education and the structural crisis of capital: the U. S. Case. Monthly Review, v. 63, n. 3, p. 6-37, 2011.

MÉSZÁROS, I. The challenge and burden of historical time: socialism in the twenty-first century. New York: Monthly Review Press, 2008.

FRIGOTTO, G. Trabalho e educação face a crise do capitalismo: ajuste neoconservador e alternativa democrática. 1994. 213 f. Tese (Concurso para professor titular) - Faculdade de Educação, Universidade Federal Fluminense, Rio de Janeiro, 1994.

HARVEY, D. Condição pós-moderna. São Paulo: Loyola, 1994.

IBGE. Pesquisa nacional por amostra de domicílios. Rio de Janeiro: IBGE, 2004.

JESSOP, B. Revisiting the regulation approach: critical reflections on the contradictions, dilemmas fixes and crises dynamics of growth regimes. Capital \& Class, v. 31, n. 1, p. 5-24, 2013.

LANZI, D. Capabilities, human capital and education. The journal of socio-economics, n. 34, p. 424-435, 2007.

MAIA FILHO. Formação para o trabalho ou formação do trabalhador? In: PINHEIRO, C. V. de Q.; CARVALHO, J. Q.; SILVA, M. F. V. Estudos psicanalíticos na clínica e no social. Fortaleza: Impressa Universitária, 2011. p. 197-230.
MARX, K. Elementos fundamentales para la crítica de la economía política (Gundrisse) 1857-1859. Ciudad de México: Siglo Veintiuno, 1989.

O capital: crítica da economia política. Rio de Janeiro: Ed. Bertrand Brasil, 1994.

MELLO, G. N. de. Diretrizes curriculares para o ensino médio: por uma escola vinculada à vida. Revista Iberoamericana de Educação, n. 20, 1999.

MENELEU NETO, J. Desemprego e luta de classes: as novas determinidades do conceito marxista de exército industrial de reserva. In: TEIXEIRA, F. J. S.; OLIVEIRA, M. A. de. (Org.). Neoliberalismo e reestruturação produtiva: as novas determinações do mundo do trabalho. São Paulo: Cortez; Fortaleza: UECE, 1996. p. 75-107.

MÉSZÁROS, I. A crise em desdobramento e a relevância de Marx. Monthly Review, 2008. Disponível em: <http://mrzine.monthlyreview.org/meszaros 041108 . html>. Acesso em: 19 fev. 2013.

Para além do capital: rumo a uma teoria da transição. São Paulo: Boitempo Editorial; Campinas: UNICAMP, 2002.

Structural crisis needs structural change. Monthly Review Archives, v. 63, n. 10, p. 27-37, mar. 2012.

The uncontrollability of globalizing capital - intro to beyond capital. Monthly Review Archives, v. 49, n. 19, p. 27-37, 1998.

PAIVA, V. Produção e qualificação para o trabalho: uma revisão bibliográfica internacional. In: DIAS, F. C. (Org.). Ensino das humanidades: a modernidade em questão. São Paulo: Cortez, 1991.

PAULO NETTO, J. Uma face contemporânea da barbárie. In: ENCONTRO INTERNACIONAL "CIVILIZAÇÃO OU BARBÁRIE”, 3., 2010, Serpa/Portugal. Anais... Serpa/Portugal: Vértice, 2010. 41 p.

BRAZ, M. Economia política: uma introdução crítica. 3. ed. São Paulo: Cortez, 2007.

RIFKIN, J. O fim dos empregos: o declínio inevitável dos níveis de emprego e a redução da força global de trabalho. São Paulo: Makron Books, 1995.

ROSDOLSKY, R. Gênese e estrutura de O capital de Karl Marx. Rio de Janeiro: EDUERJ; Contraponto, 2001. 